\title{
Cytogenic investigations in the assessment of response to treatment in neuroblastoma
}

\author{
N BOWN, M M REID, $\dagger$ A D J PEARSON,* E V DAVISON, A J MALCOLM, $\ddagger$ \\ A W CRAFT* \\ From the Departments of Human Genetics, ${ }^{*}$ Child Health and $\ddagger$ Pathology, University of Newcastle upon Tyne, \\ and $†$ Department of Haematology, Royal Victoria Infirmary, Newcastle upon Tyne
}

SUMMARY In a patient with stage IV disseminated neuroblastoma treated by chemotherapy extensive cytogenetic investigations were performed on the residual primary tumour and bone marrow immediately before myeolablative treatment and autologous marrow rescue. Two abnormal clones both showing $1 \mathrm{p}^{+}$, a characteristic abnormality of neuroblastoma, were detected in cells from the residual primary tumour, providing direct evidence of persisting viable tumour. Such investigations should be a routine part of the assessment of response to treatment in patients with neuroblastoma, and could be extended to others in whom "second look" surgery is performed.

Most children over 1 year old with disseminated neuroblastoma will succumb to resistant disease. A prominent fibrous stromal background to tumour infiltrate in the bone marrow, both at diagnosis and subsequently, is characteristic of disseminated neuroblastoma. How much of this fibrous component is reactive and how much a product of the tumour itself is still unknown. With current histological techniques, it is difficult to determine whether residual tissue in marrow or primary site still contains viable tumour after chemotherapy. The presence of clonal karyotypic abnormalities characteristic of neuroblastoma in cells from residual scar tissue would provide evidence that viable tumour cells remained. We describe a child with stage IV neuroblastoma in whom intensive cytogenetic investigation of bone marrow and residual primary tissue was carried out immediately prior to myeloablative treatment and autologous marrow rescue.

\section{Case report}

Stage IV neuroblastoma was diagnosed in a 7 year old boy: this was based on infiltration of bone marrow with non-haemopoietic cells detected in marrow aspirate and a trephine biopsy specimen, a raised urinary vanillylmandelic acid (VMA) concentration, multiple

Accepted for publication 27 May 1987 "hot" spots on bone scan, and the presence of a left adrenal primary tumour shown by ultrasound scanning. The cells in the marrow reacted with the monoclonal antibody UJ13A which detects cells of neuroectodermal origin. ${ }^{1}$ Cytogenetic analysis of bone marrow cells at diagnosis showed apparently normal karyotypes in five metaphases. He received six courses of chemotherapy consisting of cisplatinum and etoposide alternating with iphosphamide, vincristine, and adriamycin. On three occasions all four iliac crests were rebiopsied to assess response and showed a progressive decrease in frankly malignant cells but continued presence of fibrous tissue. Urinary VMA excretion returned to normal. Eight months after diagnosis he underwent a laparotomy to remove the residual shrunken primary tumour. Histological examination showed some normal adrenal tissue, fibrosis, calcification, ganglioneuroma and a few tiny foci of cells-possibly persisting neuroblastoma (fig 1). Some cells were shown by electron microscopy to contain neurosecretory granules. A decision was made to progress to myeloablative chemotherapy with high dose melphalan followed by autologous unpurged marrow rescue. At marrow harvest four further trephine biopsy specimens and aspirates of marrow were obtained for examination. No morphological evidence of continuing tumour infiltrate could be found. His marrow reconstituted and he remained well four months later. 


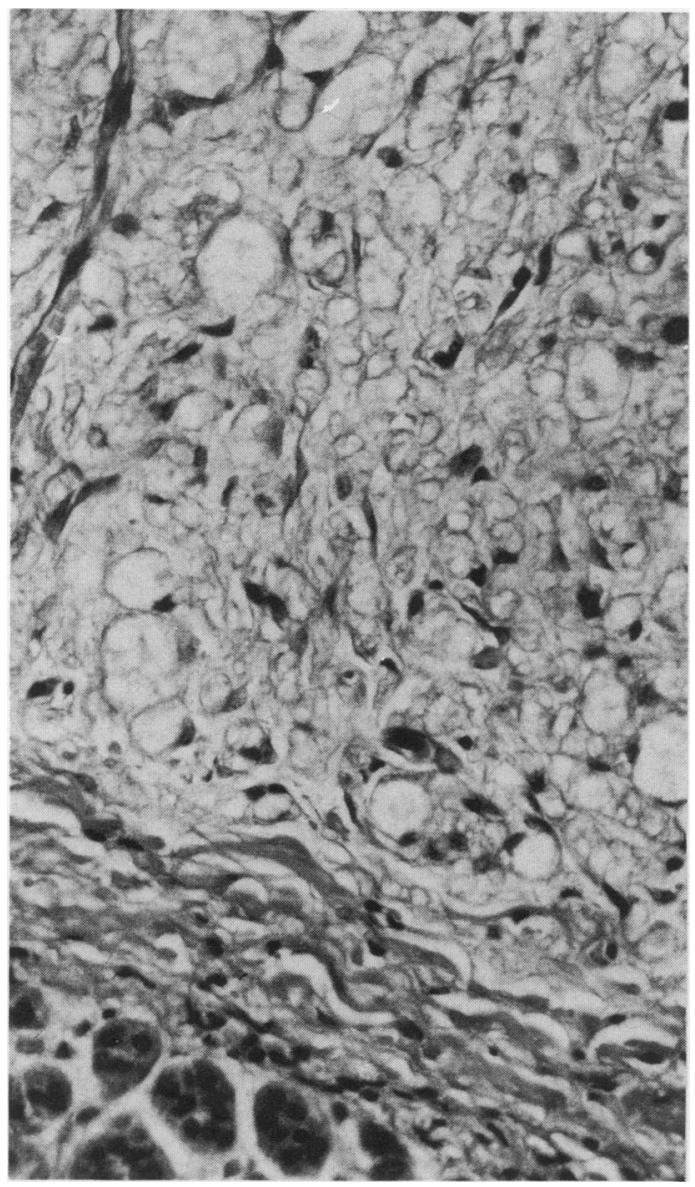

Fig 1 Section of shrunken primary tumour showing residual adrenal tissue (bottom right) and scar tissue containing ganglion cells and smaller cells that may represent persisting neuroblastoma. (Haematoxylin and eosin.)

\section{Results}

\section{BONE MARROW}

Two hundred and fifty cells were analysed. All showed an apparently normal 46XY karyotype.

\section{RESIDUAL PRIMARY TUMOUR}

Results were obtained from the long term explant cultures (table). The direct and suspension cultures all failed. Representative partial karyotypes can be seen in fig 2. The precise nature of the $1 p+$ anomaly, common to both abnormal clones, is unclear. The abnormality of chromosomes 4 and 10 takes the form of an unbalanced translocation; examination of the $10 \mathrm{q}+$ marker permitted precise description of 10pter $\rightarrow 10 \mathrm{q} 23:: 4 \mathrm{q} 11 \rightarrow 4$ qter. The small acrocentric marker is assumed to represent the $p$ arm and centromere of the deleted chromosome 4 . The origin of the extra chromosomal material on chromosome $17 p$ is unclear. Neither the $t(2 ; 12)$ nor the ?del $1 \mathrm{p},+$ marker could be confirmed as clonal.

\section{Discussion}

On morphological, biochemical, and clinical grounds this patient responded to chemotherapy. The only histological abnormalities detectable before autotransplant was carried out consisted of patches of fibrous tissue in the marrow and the possibility of a few viable tumour cells in the shrunken primary. At the time of marrow harvest there had apparently been further improvement in the bone marrow histology.

Bone marrow obtained at the harvest was karyotypically normal, but the long term explant cultures of cells from the residual primary tumour showed the presence of two karyotypically abnormal clones. Three consistent cytogenetic anomalies have previously been described in association with neuroblastoma: double minute chromosomes; homogeneously staining regions; and rearrangements of distal $1 \mathrm{p}$. Although the origin of the $1 \mathrm{p}$ anomaly in this case is not known, the chromosome is similar in appearance to that described by Cowell and Rup-

\section{Material and methods}

Bone marrow was cultured using standard techniques. The tumour tissue was cultured using direct and long term explant and suspension techniques. L15 (Gibco) and Ham's F-10 (Gibco) media were used, supplemented with $15 \%$ fetal calf serum, penicillin $(100 \mathrm{U} / \mathrm{ml})$, and streptomycin $(100 \mu \mathrm{g} / \mathrm{ml})$. Long term cultures were subcultured and harvested using conventional trypsinisation methods. Metaphase preparations were prepared after treatment with colcemid $(0.08 \mu \mathrm{g} / \mathrm{ml})$ and were stained using standard Gbanding.
Table Results of cytogenetic analysis of metaphases derived from residual primary tumour

\begin{tabular}{lcl} 
Method & No of cells & Karyotype \\
\hline Ham's F-10 culture 1 & 29 & $46, \mathrm{XY}$ \\
& 3 & $46 \mathrm{XY}, 1 \mathrm{p}+$ \\
Ham's F-10 culture 2 & 85 & $46, \mathrm{XY}$ \\
& 10 & $46, \mathrm{XY}, 1 \mathrm{p}+, \mathrm{t}(4 ; 10), 17 \mathrm{p}+$ \\
& 1 & $46, \mathrm{XY}, \mathrm{t}(2 ; 12)$ \\
L-15 culture 1 & 1 & $46 \mathrm{XY}, ?$ del $1 \mathrm{p},+$ mar \\
\hline
\end{tabular}




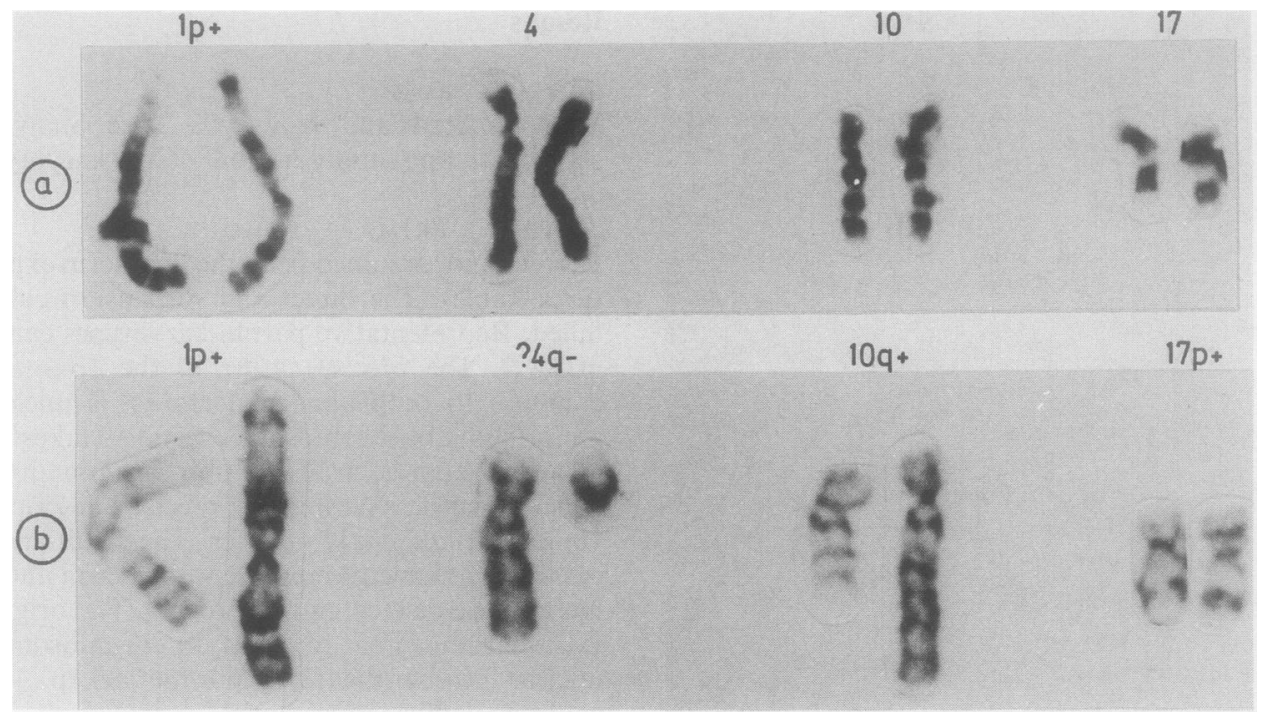

Fig 2 Partial karyotypes of abnormal clones: (a) $1 p+$ as sole abnormality in culture $1 ;(b) 1 p+, t(4 ; 10)$, and $17 p+$ in culture 2.

niak, ${ }^{2}$ who tentatively concluded that a homogeneously staining region was present distal to band 1p31. In the case reported here the $1 p+$ anomaly could equally well have resulted from the translocation on to $1 \mathrm{p}$ of other chromosomal material, but there may also have been a deletion of at least part of 1p32-1pter. Brodeur et al reported deletions of this region at a high frequency in neuroblastoma cells, ${ }^{3}$ which have subsequently been confirmed in other studies. ${ }^{4}$ The $10 \mathrm{q}$ breakpoint in the $t(4 ; 10)$ seems to be $10 \mathrm{q} 23$. This is known to be a common fragile site. ${ }^{5}$ Although there is also a common fragile site at $17 \mathrm{p} 12$, this could not be confirmed as the breakpoint in our $17 p+$ marker. No double minute chromosomes were observed in this study.

It is reasonable to assume that the 13 cells containing $1 p+$ represented viable neuroblastoma cells. The abnormalities were clonal and did not resemble those induced by chemotherapy. On the other hand, the absence of similar clonal abnormalities in the bone marrow can not be taken as evidence that the marrow was free of tumour. With the recovery of haemopoiesis, which usually accompanies chemotherapy in these children, there is considerable dilution of any persisting tumour cells. The analysis of 250 cells would exclude the presence of a clone at the $1 \%$ level with $95 \%$ confidence limits ${ }^{6}$ only if its members underwent mitoses as often as the haemopoietic cells.

This study provides direct evidence of the presence of viable tumour cells in a shrunken primary tumour and raises the possibility that similarly viable cells may be present in the residual fibrous tissue so often found in the bone marrow. When the primary tumour is removed in patients with neuroblastoma, cytogenetic investigation of any biopsy tissue should be routinely performed. Information from such studies may make unequivocal the often ambiguous remission state of many children with disseminated neuroblastoma, permit better evaluation of their response to treatment, and provide the basis for a rational approach to further treatment. This approach could be extended to patients with other solid tumours in whom "second look" surgery is performed.

We thank Dr J Kemshead for undertaking the monoclonal antibody studies at diagnosis and Newcastle Health Authority Scientific and Research Committee for funding the cytogenetic studies.

\section{References}

1 Kemshead JT, Goldman A, Fritschy J, et al. Use of panels of monoclonal antibodies in the differential diagnosis of neuroblastoma and lymphoblastic disorders. Lancet 1983;i:12-15.

2 Cowell JK, Rupniak HT. Chromosome analysis of human neuroblastoma cell line TR14 showing double minutes and an aberration involving chromosome 1. Cancer Genet Cytogenet 1983;9:273-80.

3 Brodeur GM, Green AA, Hayes FA, Williams KJ, Williams DL, Tsiatis AA. Cytogenetic features of human neuroblastomas and cell lines. Cancer Res 1981;41:4678-86.

4 Gilbert F. Solid tumours in children: chromosomal abnormalities and the development of cancer. J Cell Physiol 1984; 3(suppl): 165-70.

5 Hecht F, Sutherland GR. Fragile sites and cancer breakpoints. Cancer Genet Cytogenet 1984;12:179-81.

6 Hook EB. Exclusion of chromosomal mosaicism: tables of $90 \%$, $95 \%$ and $99 \%$ confidence limits and comments on use. Am J Hum Genet 1977;29:94-7.

Requests for reprints to: Dr MM Reid, Department of Haematology, Royal Victoria Infirmary, Newcastle upon Tyne, NE1 4LP, England. 